\title{
Nanoindentation of Graphene/Phospholipid Nanocomposite: A Molecular Dynamics Study
}

\author{
Vladislav V. Shunaev ${ }^{1}$ (D) and Olga E. Glukhova ${ }^{1,2, *}$ \\ 1 Department of Physics, Saratov State University, 410012 Saratov, Russia; shunaevvv@sgu.ru \\ 2 Institute for Bionic Technologies and Engineering, I.M. Sechenov First Moscow State Medical \\ University (Sechenov University), 119991 Moscow, Russia \\ * Correspondence: glukhovaoe@sgu.ru; Tel.: +7-8452-514562
}

check for

updates

Citation: Shunaev, V.V.; Glukhova, O.E. Nanoindentation of Graphene/Phospholipid Nanocomposite: A Molecular Dynamics Study. Molecules 2021, 26, 346. https://doi.org/10.3390/ molecules26020346

Academic Editors: Minas

M. Stylianakis and

Athanasios Skouras

Received: 14 December 2020

Accepted: 8 January 2021

Published: 11 January 2021

Publisher's Note: MDPI stays neutral with regard to jurisdictional clai$\mathrm{ms}$ in published maps and institutional affiliations.

Copyright: $(\odot 2021$ by the authors. Licensee MDPI, Basel, Switzerland. This article is an open access article distributed under the terms and conditions of the Creative Commons Attribution (CC BY) license (https:// creativecommons.org/licenses/by/ $4.0 /)$.

\begin{abstract}
Graphene and phospholipids are widely used in biosensing and drug delivery. This paper studies the mechanical and electronic properties of a composite based on two graphene flakes and dipalmitoylphosphatidylcholine (DPPC) phospholipid molecules located between them via combination of various mathematical modeling methods. Molecular dynamics simulation showed that an adhesion between bilayer graphene and DPCC increases during nanoindentation of the composite by a carbon nanotube (CNT). Herewith, the DPPC molecule located under a nanotip takes the form of graphene and is not destroyed. By the Mulliken procedure, it was shown that the phospholipid molecules act as a "buffer" of charge between two graphene sheets and CNT. The highest values of electron transfer in the graphene/DPPC system were observed at the lower indentation point, when the deflection reached its maximum value.
\end{abstract}

Keywords: graphene; phospholipids; molecular dynamics; nanoindentation; local stress; electron transfer

\section{Introduction}

Graphene is a two-dimensional allotropic modification of carbon with a thickness of one atom [1]. High biocompatibility [2], unique adsorption properties [3,4], and large surface area of graphene allow it to form a compatible interface with phospholipid molecules [5-8]. Both graphene and phospholipids separately are widely used in biosensing [9-13] and drug delivery [14-16]. It is predicted that the synergistic effect of graphene and phospholipids could be used in various biomedical devices [17-21].

Simulation of graphene-based composites' nanoindentation by molecular dynamic methods allows to study local characteristics of the considered objects, as it makes it possible to place a nanotip strictly above the surface of interest. Huang et al. MD research showed that the strength and hardness of bio-inspired nanocomposites decreased with the increasing length of graphene layers, while increasing the length of the graphene layer avoids the generation of dislocations at the edge of the graphene sheet [22]. Nanoindentation of $\mathrm{Cu} / \mathrm{Gr}$ layered nanopillars allowed to find the dependence of the composite mechanical properties on the specified boundary conditions and anomalous extrinsic size effect- the weakening influence caused by the dislocations at the edges of graphene was compensated by hardening of graphene in the middle of the sheet [23]. Peng et al. demonstrated that the strength of a copper substrate during indentation dramatically depended on the number of graphene layers on its surface [24]. Simulation of lipid bilayer and graphene under indentation loads has shown that a graphene coating could effectively maintain the structural and physiological stability of a bio-nanohybrid [25]. Modeling of nanoindentation showed the strengthening effect of graphene coverage on a nickel substrate [26].

The object of this study is a composite based on two graphene flakes and dipalmitoylphosphatidylcholine (DPPC) phospholipid molecules located between them. Pre- 
viously, the authors found the configurations of such composites that provide optimal current-voltage characteristics and electron transfer values [27]. The aim of this work is to simulate nanoindentation of the bilayer graphene/DPPC composite with subsequent evaluation of the mechanical and electronic properties during deflection.

\section{Results}

\subsection{Atomistic Model}

At the initial stage, two DPPC molecules containing 1 phosphorus atom, 1 nitrogen atom, 8 oxygen atoms, 40 carbon atoms, and 80 hydrogen atoms were placed between two graphene monolayer flakes with dimensions $\mathrm{L}_{x} \times \mathrm{L}_{\mathrm{y}}=25.5 \AA \times 35.51 \AA$. This composite structure acted as the supercell with translation vectors $\mathrm{L}_{\mathrm{x}}, \mathrm{L}_{\mathrm{y}}$ (Figure 1a). This supercell contained 878 atoms, 618 of which belonged to graphene, and 260 to the DPPC molecules. The geometric center of each DPPC molecule was located at a distance of $6.23 \AA$ from each graphene sheet. The atomic structure of the designed supercell and the values of the translation vectors were optimized by the self-consistent charge density functional tight-binding (SCC DFTB) 2 method.

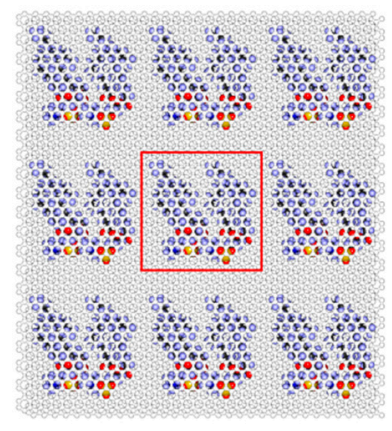

(a)

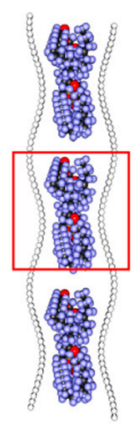

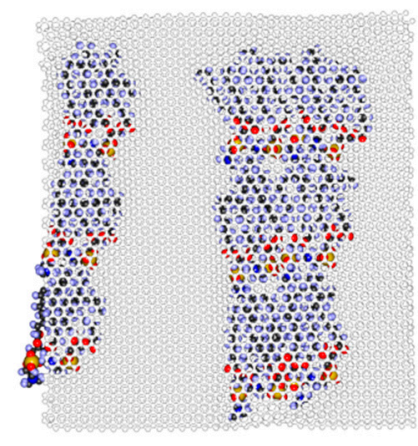

(b)

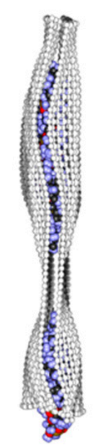

Figure 1. Atomic structure of the graphene/dipalmitoylphosphatidylcholine (DPPC) composite: (a) before the optimization; (b) type I after the optimization; and (c) type II after the optimization. The supercell obtained by the self-consistent charge density functional tight-binding (SCC DFTB) 2 method is highlighted by the red box. Graphene atoms are grey, phosphorous—yellow, nitrogen—blue, oxygen—red, carbon in phospholipid—black, and hydrogen—blue.

The fragment of a graphene/DPPC composite film containing 7902 atoms was built from nine optimized supercells. The fragment sizes were $90.46 \AA \times 80.56 \AA$, and the initial structure is shown in Figure 1a. As the search for the ground state of such a polyatomic fragment by the SCC DFTB 2 quantum mechanical method is practically impossible, the AMBER empirical method was applied. It should be noted that the fragment is not a supercell, but a finite structure. From the result of 20 numerical experiments of the graphene/DPPC composite optimization, two types of object's topology were identified. In the type I topology, 12 DPPC molecules formed a disordered bundle (Figure 1b). If an additional number of DPPC molecules are added to the composite, double and triple layers of lipids can be formed in this structure [5]. In the type II topology, the phospholipids were arranged in a shape vaguely resembling a spiral; part of one DPPC even left the pores between the graphene sheets (Figure 1c). During optimization, the total energy of the system decreased from 17.54 , to $3.967 \mathrm{Mcal} / \mathrm{mol}$ and the adhesion energy between graphene flakes and DPPC molecules dropped from -896.115 to $-4124.72 \mathrm{kcal} / \mathrm{mol}$. Because, in this structure, two isolated DPPC molecules located in the center of the composite were clearly distinguished, it was chosen as the object of nanotip indentation.

\subsection{Nanoindentation}

At the next stage, the carbon nanotube (CNT) $(16,0)$ with a closed edge was placed at a distance of $4.1 \AA$ from the surface of the upper graphene sheet (Figure 2a). The length of 
the CNT was $50.62 \AA$. To perform the process of the composite material indentation, the nanotip approached the composite surface with a step of $0.5 \AA$. At each step, the process of relaxation scanning was started, the values of local stresses on the atoms were determined, and the adhesion energy between bilayer graphene and phospholipids was calculated. Based on the analysis of the above-mentioned characteristics, the so-called "key points" of indentation were identified (Table 1).
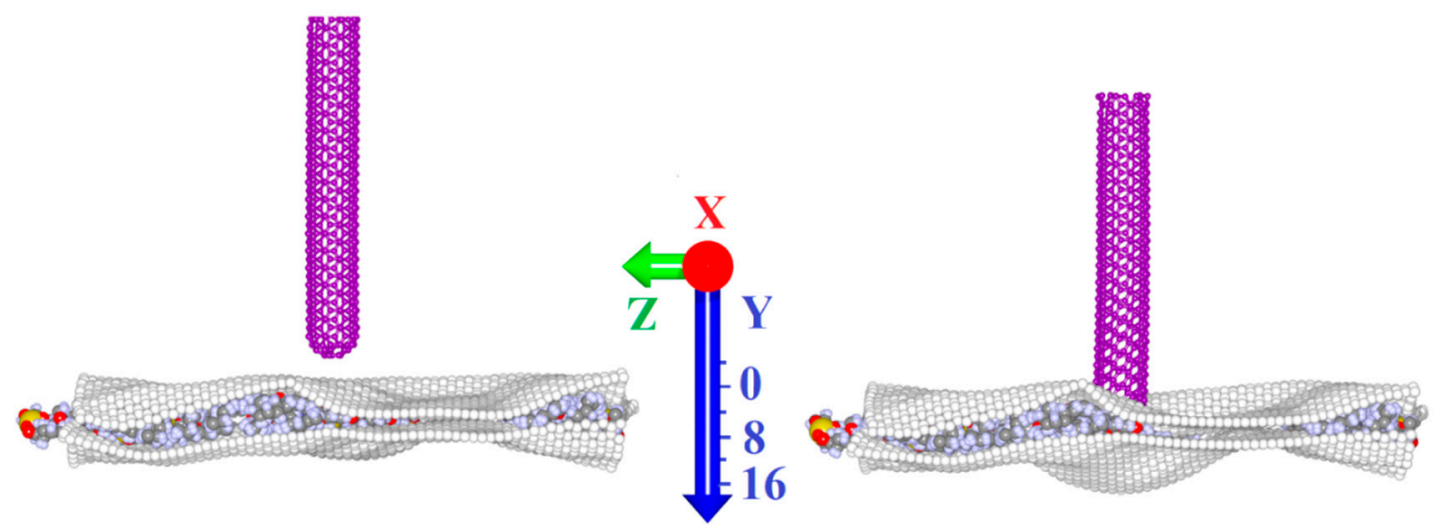

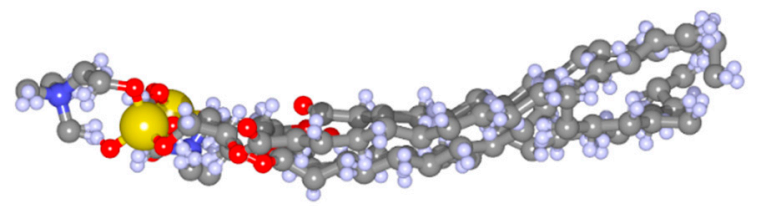

(b)

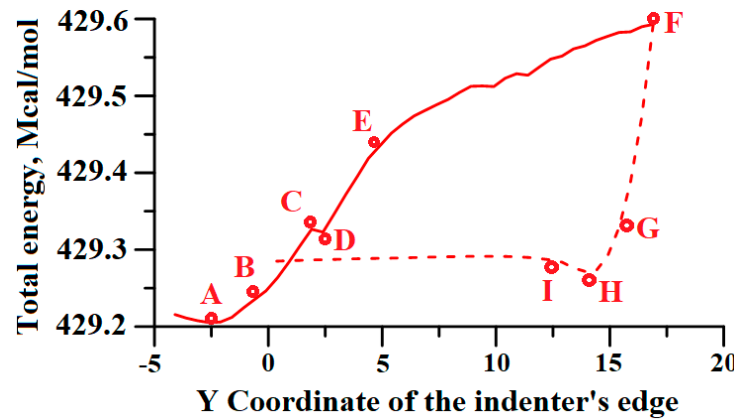

(c)

Figure 2. Nanoindentation of the composite graphene/DPPC by the carbon nanotube (CNT) with a closed edge: (a) initial (left) and last (right) point of indentation F; (b) the atomic structure of the central DPPC molecule at point F; and (c) the dependence of the system's total energy on the CNT shift. The solid line corresponds to the forward stroke (FS) and the dotted line corresponds to the reverse. At the initial point, the edge of the CNT had the coordinate $\mathrm{Y}=0$, and the atoms of the upper graphene layer had the coordinate $\mathrm{Y}=-4.1 \AA$.

Table 1. Key points of the nanoindentation with corresponding $Y$ coordinates; the values of the adhesion energy between bilayer graphene and dipalmitoylphosphatidylcholine (DPPC) molecules and maximum local stresses (MLSs) in these points. The abbreviation FS corresponds to forward stroke and RS corresponds to reverse stroke.

\begin{tabular}{cccc}
\hline Key Point & $\begin{array}{c}\text { Y Coordinate of the } \\
\text { Indenter's Edge, } \AA\end{array}$ & $\begin{array}{c}\text { Energy of Adhesion between Bilayer } \\
\text { Graphene and Phospholipid, kcal/mol }\end{array}$ & MLS, GPa \\
\hline A & $-2.6(\mathrm{FS})$ & -4125.1 & 0.2 \\
B & $-0.6(\mathrm{FS})$ & -4124.03 & 0.47 \\
$\mathbf{C}$ & $1.9(\mathrm{FS})$ & -4125.85 & 1.53 \\
$\mathbf{D}$ & $2.4(\mathrm{FS})$ & -4127.13 & 1.71 \\
E & $4.4(\mathrm{FS})$ & -4114.53 & 2.25 \\
F & $17.4(\mathrm{FS})$ & -4116.33 & 2.53 \\
G & $15.4(\mathrm{RS})$ & -4166.4 & 0.89 \\
H & $13.4(\mathrm{RS})$ & -4172.05 & 0.97 \\
I & $12.4(\mathrm{RS})$ & -4172.45 & 0.97 \\
\hline
\end{tabular}


The dependence of the system's total energy on the CNT shift is shown in Figure 2c. A local minimum was observed at point $\mathrm{A}$, indicating the most energetically favorable location between the CNT and the composite owing to the van der Waals (vdW) interaction. Further, the energy grew steadily until it reached point $C$. Between points $C$ and $\mathrm{D}$, there was a slight drop in the total energy of the system. In this region, the atomic structure of the DPPC molecule was rearranged and it started to take the form of graphene (Figure 2b). Note that, during the forward stroke, the adhesion energy between graphene and DPPC molecules reached its maximum value precisely at point $\mathrm{D}$ (Table 1). The position of CNTs at the lower indentation point $\mathrm{F}$ is shown in Figure 2a on the right. As the CNT left the trough of the composite (reverse stroke), the energy decreased greatly (from F to $\mathrm{H}$ ). At this interval, the CNT tip stopped to pressurize the composite and began to relax. The point $\mathrm{H}$ corresponds to the moment of the strongest vdW interaction between objects during reverse stroke, so the local minimum of the total energy at this point is observed. Then, the vdW interaction became weaker and, from a certain moment (point I), the total energy practically did not change. Note that the trough created by the nanotip in the composite remained even after the CNT returned to its initial position. Herewith, the remaining 16 DPPC molecules did not leave the space between the graphene sheets (Figure 2a). The value of the adhesion energy between graphene and DPPC molecules at point I and further remained at the maximum for the entire time. Thus, despite the fact that no chemical bonds between graphene and DPPC molecules were formed during indentation, the bonds between graphene sheets and DPPC molecules were significantly strengthened.

\subsection{Analysis of Graphene Sheets Strength during Nanoindentation}

To assess the strength of graphene sheets during deflection, we calculated the map of the local stresses' distribution by atoms at each step (Figure 3a-h). As the maximum values of local stresses (MLSs) were found in the central atoms of the sheets (under nanotip), we presented maps only for these regions. Figure 3i shows the graph of the MLS on graphene atoms dependence on the indentation step. From the beginning of indentation to point B, the MLSs were observed in the upper sheet of graphene and varied from 0 to $0.47 \mathrm{GPa}$. Such minor changes were caused by the fact that the CNT has not yet reached the surface of the upper graphene sheet. The dependence on the BE section was almost linear, which indicated the elastic nature of the deformation. In this segment, the central phospholipid molecule under the CNT has taken the form of the curved graphene sheet. At the same time, there was significant increase in the MLS from 0.46 to $2.25 \mathrm{GPa}$. Therefore, at the $\mathrm{BE}$ segment, the graphene sheets started to provide a strengthening effect on the DPPC molecule, not allowing it to destruct under the influence of the nanotip. After this point, the adhesion between graphene and DPPC increased (see Section 2.2) and the MLS did not change much; on the EF segment, the MLS increased from 2.25 to 2.53 GPA. During the reverse stroke, a sharp drop in the MLS from 2.53 to 0.86 GPA was observed between F and G. At this interval, the composite started to relax because pressure from the tip became weaker (see Section 2.2). Starting from point G, the MLSs were observed in the lower graphene sheet and, starting from point $\mathrm{H}$, the MLS values stopped changing because the energy of the vdW interaction between objects reached a minimum. 


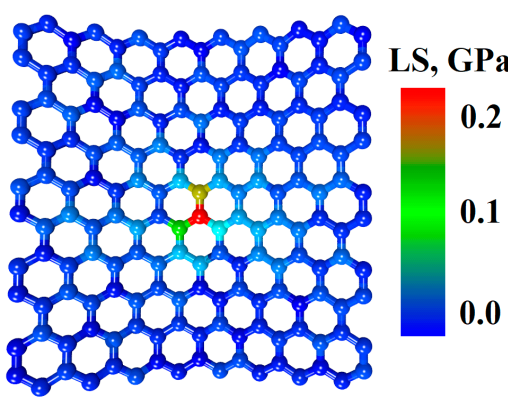

(a)

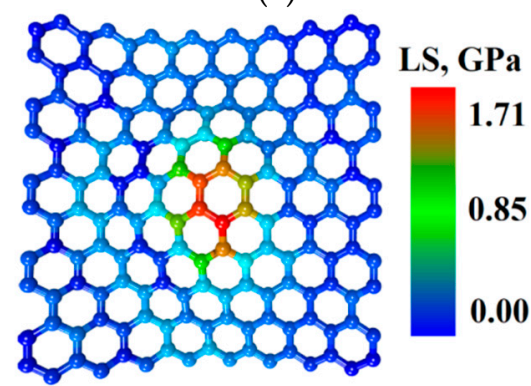

(d)

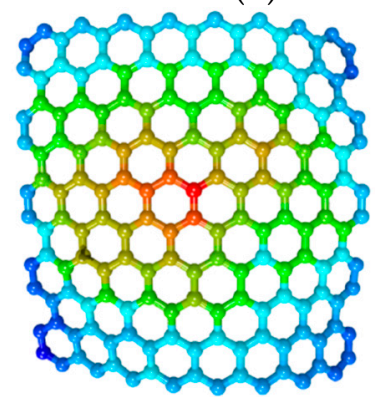

(g)

LS, GPa

0.89

0.45

0.00

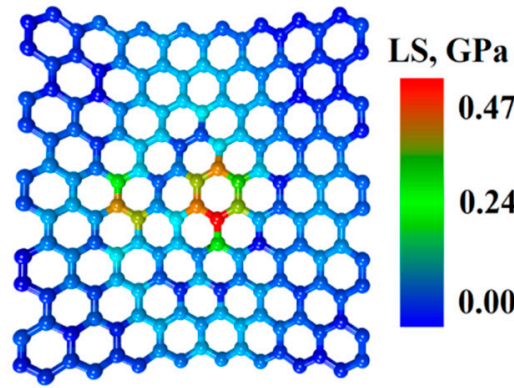

(b)

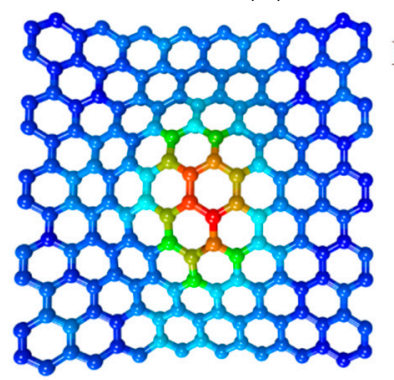

(e)

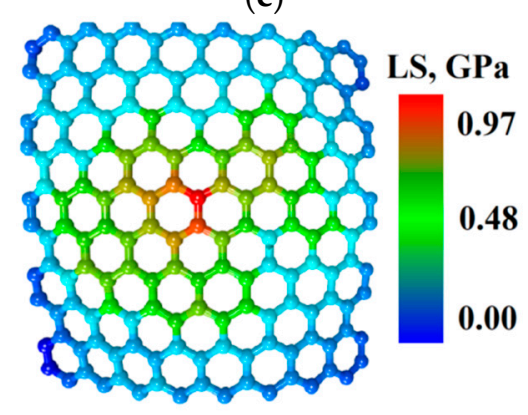

(h)

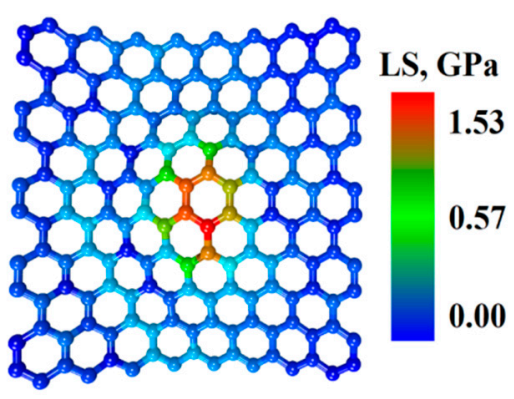

(c)

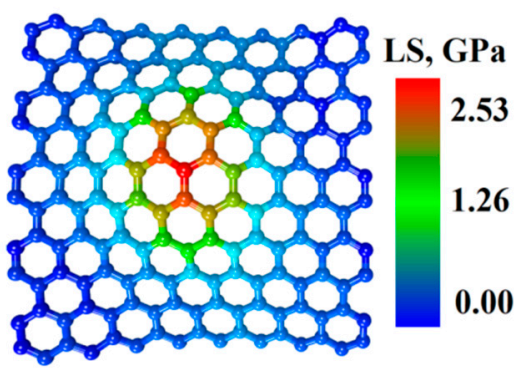

(f)

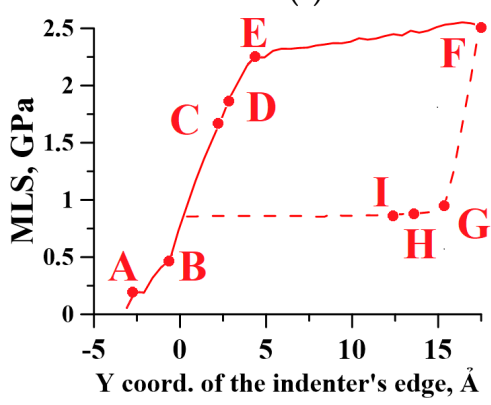

(i)

Figure 3. The map of the local stress (LS) in the central area of the graphene sheets at the key points of indentation: (a) point A; (b) point B (upper layer); (c) point C (upper layer); (d) point D (upper layer); (e) point E (upper layer); (f) point $\mathrm{F}$ (upper layer); (g) point G (lower layer); (h) point H (lower layer); and (i) the dependence of the maximum local stress (MLS) in graphene sheet atoms on the indentation step (the solid line corresponds to the forward stroke and the dotted line corresponds to the reverse).

\subsection{Analysis of Electron Transfer in the CNT/Graphene/DPPC System during Nanoindentation}

As the calculation of atoms' Mulliken charges by the SCC DFTB 2 method is resource consuming, the central part was cut out from the graphene/DPPC composite. This fragment containing two isolated DPPC molecules directly contacted the CNT and was responsible for charge transfer in the system (Figure $4 \mathrm{a}$ ). 

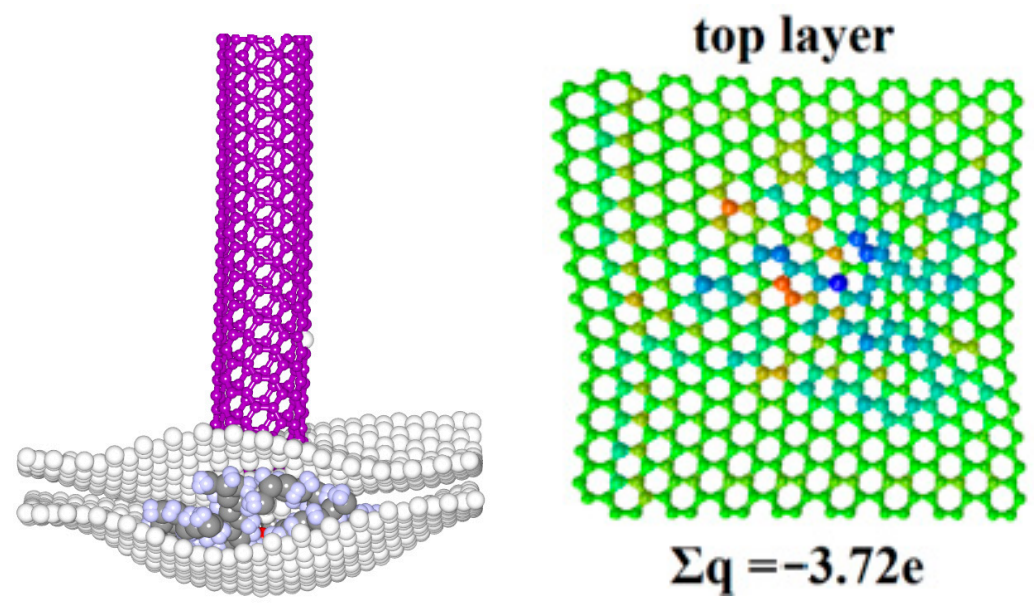

(a)

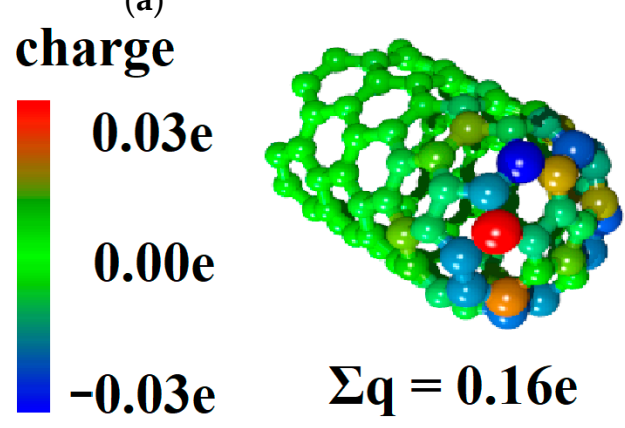

(c)

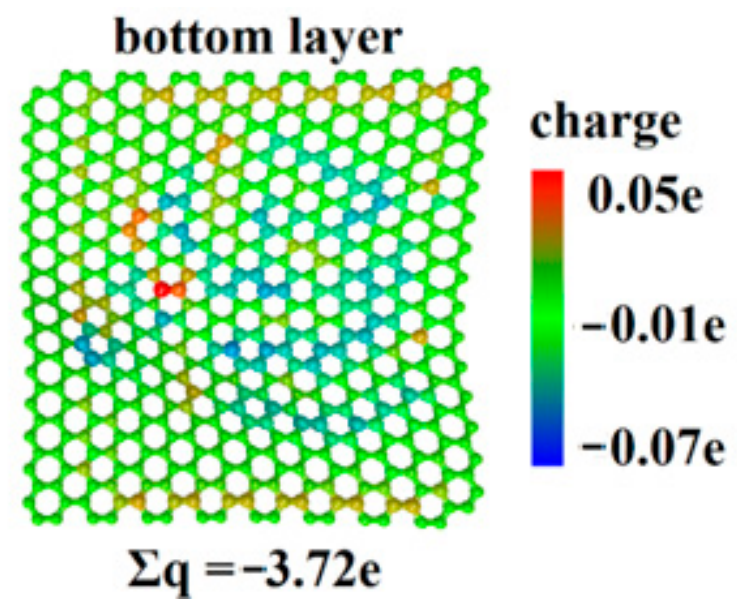

(b)

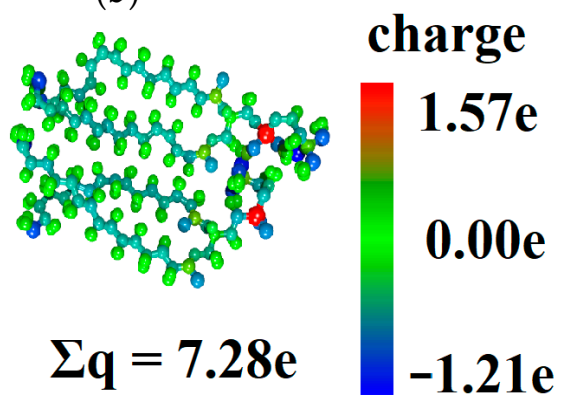

(d)

Figure 4. The analysis of the electron transfer in the CNT/graphene/DPPC system during nanoindentation (a) The fragment of the atomic structure graphene/DPPC with CNT at point F; (b) the distribution of Mulliken charges on atoms in the point for the upper (left) and the lower (right) graphene sheets; (c) for CNT; and (d) for DPPC.

The charge distributions between the atoms at the initial moment of time, at the lower point of the forward stroke F, and at the end of the reverse stroke I are shown in Table 2 At the initial moment of time, the CNT was electrically neutral. In the composite, the DPPC molecules acted as a donor and transferred the charge of 6.09 e to graphene sheets; the largest part of the charge was lost by two P-atoms (1.61 and $1.65 \mathrm{e})$, which is consistent with the results obtained earlier [26]. The charge between the graphene sheets was distributed unevenly because of the orientation of the DPPC molecules after optimization-the phosphorus molecules that tend to give charge and act as donors were located closer to the upper graphene sheet. During the indentation, the CNT gradually transferred the charge to the composite; at the lower point, its value was 0.16 e (Figure 4c). It can be seen that the phospholipid transferred even more charge to graphene sheets than in the initial state (7.28 e) (Figure 4d). The charge transferred from DPPC was evenly distributed between the graphene sheets (Figure $4 \mathrm{~b}$ ). This was caused by the fact that the DPPC molecules have taken the form of graphene sheets, as shown in Section 2.2, and the P atoms were located at the same distance from the graphene sheets. As the CNT is removed from the composite, it recovered the transferred charge and eventually became almost electroneutral again. Note that, during the reverse stroke, the main part of the charge came from the upper sheet of graphene that was directly in contact with the CNT. Thus, the DPPC molecules stopped to act as a "buffer" of charge between the two graphene sheets. The highest values of electron transfer in the graphene/DPPC system were observed at the lower indentation point, when the deflection reached its maximum value. Based on the conclusions of [26], it can be concluded that the deflection strain would significantly affect the current-voltage characteristics of the considered composite. 
Table 2. Distribution of Mulliken charge in the system CNT/graphene/DPCC at different moments of nanoindentation. CNT, carbon nanotube.

\begin{tabular}{ccccc}
\hline & CNT & $\begin{array}{c}\text { Upper Layer of } \\
\text { Graphene Sheet }\end{array}$ & DPPC & $\begin{array}{c}\text { Lower Layer of } \\
\text { Graphene Sheet }\end{array}$ \\
\hline Initial moment of time & $0.00 \mathrm{e}$ & $-3.45 \mathrm{e}$ & $6.09 \mathrm{e}$ & $-2.63 \mathrm{e}$ \\
Point F & $0.16 \mathrm{e}$ & $-3.72 \mathrm{e}$ & $7.28 \mathrm{e}$ & $-3.72 \mathrm{e}$ \\
Point I & $-0.01 \mathrm{e}$ & $-3.28 \mathrm{e}$ & $6.87 \mathrm{e}$ & $-3.58 \mathrm{e}$ \\
\hline
\end{tabular}

\section{Methods}

The search for the ground state of the graphene/DPPC composite film, as well as the study of its atomic structure changes during deflection by a nanotip, was performed by the AMBER empirical method [28] implemented in the Hyperchem software package [29]. Optimization was performed by the conjugate gradient Fletcher-Reeves method, and the root mean square (RMS) gradient was $0.1 \mathrm{kcal} /(\mathrm{A} \cdot \mathrm{mol})$.

The adhesion energy between the phospholipids and graphene sheets at various steps was calculated by the following formula (Equation (1)):

$$
E_{A D H}=E_{T O T}-E_{D P P C}-E_{U P}-E_{L O W}
$$

where $E_{T O T}$ is the energy of the graphene/DPPC system at this point, and $E_{D P P C}, E_{U P}$, and $E_{L O W}$ are the energies of isolated DPPC, upper, and lower graphene sheets, respectively.

To estimate the strength of graphene sheets during deflection, the previously developed original method for calculating local stresses of the atomic grid was used [30]. According to this method, the stress $\sigma_{i}$ on each atom is calculated by the formula $\sigma_{i}=\left|w_{i}-w_{0}\right|$, where $w_{0}$ is the energy volume density of the graphene atom before indentation, and $w_{i}$ is the energy volume density of the graphene atom under external influence. The energy volume density of the atom was calculated by the formula $w_{i}=\frac{E_{i}}{V_{i}}$, where $E_{i}$ is the energy of the atom calculated within the AMBER force field, and $V_{i}=\frac{4 \pi r^{3}}{3}$ is the volume of the carbon atom $(r=1.7 \AA)$.

The study of changes in the electronic structure during indentation and electronic transfer between phospholipid molecules and graphene was performed by Mulliken population analysis [31]. According to this method, the charge on an atom is calculated as the difference between the atomic number $Z_{A}$ and $G A P_{A}$-the sum of the gross orbital product over all orbitals belonging to atom $A: Z=Z_{A}-G A P_{A}$. The charges were calculated by the quantum mechanical self-consistent charge density functional tightbinding (SCC DFTB) method [32] in the dftb+ software package [33] in the 3ob-3-1 basis.

\section{Conclusions}

The nanoindentation of the composite on the base of bilayer graphene and 16 DPPC phospholipid molecules was simulated by the molecular dynamics method. It was noted that, during indentation, the adhesion between graphene flakes and DPPC molecules increased and reached a maximum at the end of the reverse stroke. The maximum values of local stresses (in the region of 2.53 GPA) were observed on the upper graphene layer at the lower indentation point. At this moment, the DPPC molecule located under the nanotip took the form of curved graphene, while chemical bonds of the phospholipid molecules were not destroyed. The pressure of the CNT tip led to the growth of adhesion energy between graphene sheets and DPPC molecules. It is known that, getting into blood vessels, drug carriers sense abnormally high shear stresses [34,35], so the discovered effect of "phospholipid strengthening" by the graphene sheets' coating can be used in the field of drug delivery. It was found that the electron transfer between CNT and graphene/DPPC composites increased during indentation and reached $0.16 \mathrm{e}$. At this moment, the phospholipid molecule stopped to act as a "buffer" of charge between the 
two graphene sheets. The observed phenomenon of electronic transfer between graphene and phospholipid can be applied in biosensorics.

Author Contributions: Conceptualization, O.E.G.; methodology, O.E.G.; software, V.V.S.; validation, O.E.G. and V.V.S.; formal analysis, O.E.G.; investigation, V.V.S. and O.E.G.; resources, O.E.G.; data curation, V.V.S.; writing — original draft preparation, V.V.S. and O.E.G.; writing—review and editing, V.V.S.; visualization, V.V.S.; supervision, O.E.G.; project administration, O.E.G.; funding acquisition, O.E.G. All authors have read and agreed to the published version of the manuscript.

Funding: This research was funded by the Ministry of Science and Higher Education of the Russian Federation (project no. FSRR-2020-0004).

Institutional Review Board Statement: Not applicable.

Informed Consent Statement: Not applicable.

Data Availability Statement: The data presented in this study is available in this article.

Conflicts of Interest: The authors declare no conflict of interest.

\section{References}

1. Geim, A.K.; Novoselov, K.S. The rise of graphene. Nat. Mater. 2007, 6, 183-191. [CrossRef] [PubMed]

2. Pinto, A.M.; Goncalves, I.C.; Magalhaes, F.D. The rise of graphene. Colloid. Surface. B 2013, 11, 188-202. [CrossRef] [PubMed]

3. Stergiou, A.; Cantón-Vitoria, R.; Psarrou, M.N.; Economopoulos, S.P.; Tagmatarchis, N. Functionalized graphene and targeted applications-Highlighting the road from chemistry to applications. Prog. Mater. Sci. 2020, 114, 100683.

4. Nandanapalli, K.R.; Mudusu, D.; Lee, S. Functionalization of graphene layers and advancements in device applications. Carbon 2019, 152, 954-985. [CrossRef]

5. Rivela, T.; Yesylevskyy, S.O.; Ramseyer, C. Structures of single, double and triple layers of lipids adsorbed on graphene: Insights from all-atom molecular dynamics simulations. Carbon 2017, 118, 358-369. [CrossRef]

6. Lima, L.M.C.; Fu, W.; Jiang, L.; Kros, A.; Schneider, G.F. Graphene-stabilized lipid monolayer heterostructures: A novel biomembrane superstructure. Nanoscale 2016, 8, 18646-18653.

7. Li, W.; Moon, S.; Wojcik, M.; Xu, K. Direct Optical Visualization of Graphene and Its Nanoscale Defects on Transparent Substrates. Nano Lett. 2016, 16, 5022-5026. [CrossRef]

8. Okamoto, Y.; Tsuzuki, K.; Iwasa, S.; Ishikawa, R.; Sandhu, A.; Tero, R. Fabrication of Supported Lipid Bilayer on Graphene Oxide. J. Phys. Conf. Ser. 2012, 352, 012017. [CrossRef]

9. Mitsakakis, K.; Sekula-Neuner, S.; Lenhert, S.; Fuchs, H.; Gizeli, E. Convergence of Dip-Pen Nanolithography and Acoustic Biosensors towards a Rapid-Analysis Multi-Sample Microsystem. Analyst 2012, 137, 3076-3082. [CrossRef]

10. Bog, U.; Laue, T.; Grossmann, T.; Beck, T.; Wienhold, T.; Richter, B.; Hirtz, M.; Fuchs, H.; Kalt, H.; Mappes, T. On-Chip Microlasers for Biomolecular Detection via Highly Localized Deposition of a Multifunctional Phospholipid Ink. Lab Chip 2013, 13, $2701-2707$. [CrossRef]

11. Bog, U.; Brinkmann, F.; Wondimu, S.F.; Wienhold, T.; Kraemmer, S.; Koos, C.; Kalt, H.; Hirtz, M.; Fuchs, H.; Koeber, S.; et al. Densely Packed Microgoblet Laser Pairs for Cross-Referenced Biomolecular Detection. Adv. Sci. 2015, 2, 1500066. [CrossRef] [PubMed]

12. Lahcen, A.A.; Rauf, S.; Beduk, T.; Durmus, C.; Aljedaibi, A.; Timur, S.; Alshareef, H.N.; Amine, A.; Wolfbeis, O.S.; Salama, K.N.; et al. Electrochemical sensors and biosensors using laser-derived graphene: A comprehensive review. Biosens. Bioelectron. 2020, 168, 112565. [CrossRef] [PubMed]

13. Walther, B.K.; Dinu, C.Z.; Guldi, D.M.; Sergeyev, V.G.; Creager, S.E.; Cooke, J.P.; Guiseppi-Elie, A. Nanobiosensing with graphene and carbon quantum dots: Recent advances. Mater. Today 2020, 39, 23-46. [CrossRef]

14. Chauhan, G.; Shaik, A.A.; Kulkarni, N.S.; Gupta, V. The preparation of lipid-based drug delivery system using melt extrusion. Drug Discov. Today 2020, 25, 1930-1946.

15. Singh, R.P.; Gangadharappa, H.V.; Mruthunjaya, K. Phospholipids: Unique carriers for drug delivery systems. J. Drug Deliv. Sci. Technol. 2017, 39, 166-179. [CrossRef]

16. Song, S.; Shen, H.; Wang, Y.; Chu, X.; Xie, J.; Zhou, N.; Shen, J. Biomedical application of graphene: From drug delivery, tumor therapy, to theranostics. Colloid. Surface. B 2020, 185, 110596. [CrossRef]

17. Willems, N.; Urtizberea, A.; Verre, A.F.; Iliut, M.; Lelimousin, M.; Hirtz, M.; Vijayaraghavan, A.; Sansom, M.S.P. Biomimetic Phospholipid Membrane Organization on Graphene and Graphene Oxide Surfaces: A Molecular Dynamics Simulation Study. ACS Nano 2017, 11, 1613-1625.

18. Monasterio, B.G.; Alonso, B.; Sot, J.; García-Arribas, A.B.; Gil-Cartón, D.; Valle, M.; Zurutuza, A.; Goñi, F.M. Coating graphene oxide with lipid bilayers greatly decreases its hemolytic properties. Langmuir 2017, 33, 8181-8191. [CrossRef] 
19. Durso, M.; Borrachero-Conejo, A.I.; Bettini, C.; Treossi, E.; Scidà, A.; Saracino, E.; Gazzano, M.; Christian, M.; Morandi, V.; Tuci, G.; et al. Biomimetic graphene for enhanced interaction with the external membrane of astrocytes. J. Mater. Chem. $B$ 2018, 6, 5335-5342. [CrossRef]

20. Hai, L.; He, D.; He, X.; Wang, K.; Yang, X.; Liu, J.; Cheng, H.; Huang, X.; Shangguan, J. Facile fabrication of a resveratrol loaded phospholipid@reduced graphene oxide nanoassembly for targeted and near-infrared laser-triggered chemo/photothermal synergistic therapy of cancer in vivo. J. Mater. Chem. B 2017, 5, 5783-5792. [CrossRef]

21. Kuo, C.J.; Chiang, H.C.; Tseng, C.A.; Chang, C.; Ulaganathan, R.K.; Ling, T.-T.; Chang, Y.-J.; Chen, C.-C.; Chen, Y.-R.; Chen, Y.T. Lipid-modified graphene-transistor biosensor for monitoring amyloid- aggregation. ACS Appl. Mater. Interfaces 2018, 10, 12311-12316. [CrossRef]

22. Huang, Y.; Yanga, Z.; Lu, Z. Nanoindentation of bio-inspired graphene/nickel nanocomposites: A molecular dynamics simulation. Comput. Mater. Sci. 2021, 186, 109969. [CrossRef]

23. Shuang, F.; Aifantis, K.E. Dislocation-graphene interactions in $\mathrm{Cu}$ /graphene composites and the effect of boundary conditions: A molecular dynamics study. Carbon 2021, 172, 50-70. [CrossRef]

24. Peng, W.; Sun, K.; Zhang, M.; Shi, J.; Chen, J. Effects of graphene coating on the plastic deformation of single crystal copper nano-cuboid under different nanoindentation modes. Mater. Chem. Phys. 2019, 225, 1-7. [CrossRef]

25. Song, Z.; Wang, Y.; Xu, Z. Mechanical responses of the bio-nano interface: A molecular dynamics study of graphene-coated lipid membrane. Theor. Appl. Mech. Lett. 2015, 5, 231-235. [CrossRef]

26. Yan, Y.; Zhou, S.; Liu, S. Atomistic simulation on nanomechanical response of indented graphene/nickel system. Comput. Mater. Sci. 2017, 130, 16-20.

27. Slepchenkov, M.M.; Glukhova, O.E. Improving the Sensory Properties of Layered Phospholipid-Graphene Films Due to the Curvature of Graphene Layers. Polymers 2020, 12, 1710. [CrossRef]

28. Cornell, W.D.; Cieplak, P.; Bayly, C.I. A Second Generation Force Field for the Simulation of Proteins, Nucleic Acids, and Organic Molecules. J. Am. Chem. Soc. 1995, 117, 5179-5197. [CrossRef]

29. Chemistry Software, HyperChem, Molecular Modeling. Available online: http:/ /www.hyper.com/ (accessed on 1 December 2020).

30. Slepchenkov, M.M.; Glukhova, O.E. Influence of the curvature of deformed graphene nanoribbons on their electronic and adsorptive properties: Theoretical investigation based on the analysis of the local stress field for an atomic grid. Nanoscale 2012, 11, 3335-3344.

31. Mulliken, R.S. Electronic Population Analysis on LCAO-MO Molecular Wave Functions. J. Chem. Phys. 1995, 23, 1833-1840.

32. Elstner, M.; Porezag, D.; Jungnickel, G.; Elsner, J.; Haugk, M.; Frauenheim, T.; Suhai, S.; Seifert, G. Self-consistent-charge density-functional tight-binding method for simulations of complex materials properties. Phys. Rev. B 1998, 58, 7260-7268. [CrossRef]

33. DFTB $^{+}$Density Functional Based Tight Binding. Available online: https:/ / dftbplus.org (accessed on 1 December 2020).

34. Xia, Y.; Shi, C.-Y.; Xiong, W.; Hou, X.-L.; Fang, J.G.; Wang, W. Shear Stress-sensitive Carriers for Localized Drug Delivery. Curr. Pharm. Des. 2016, 22, 5855-5867. [PubMed]

35. Godoy-Gallardo, M.; Ek, P.K.; Jansman, M.M.T.; Wohl, B.M.; Hosta-Rigau, L. Interaction between drug delivery vehicles and cells under the effect of shear stress. Biomicrofluidics 2015, 9, 052605. [CrossRef] [PubMed] 